\title{
Comparison of Personal Profile and Risk Factors between Patients with Ischaemic and Haemorrhagic Stroke
}

\author{
ABU SHAMS MD. HASAN ALI MASUM ${ }^{1}$,KAZI JANNAT ARA ${ }^{2}$, ATIASAEED ${ }^{3}$, SHAKIL SHAMS $^{4}$, MD MOHIUDDIN ${ }^{5}$, \\ MA HANNAN ${ }^{2}$, MD. SHAHIDULLAH (SABUJ) ${ }^{2}$, NILUFAR FATEMA ${ }^{6}$ \\ ${ }^{1}$ Department of Neurology, Anwer Khan Modern Medical College, Dhaka, ${ }^{2}$ Department of Neurology, Bangabandhu Sheikh \\ Mujib Medical University (BSMMU), ${ }^{3}$ Department of Gastroenterology, Anwer Khan Modern Medical College, \\ ${ }^{4}$ Department of Anatomy, Dhaka Medical College Hospital, ${ }^{5}$ Department of Nephology, Anwer Khan Modern Medical College, \\ ${ }^{6}$ Department of Cardiology, BSMMU. \\ Address of Corresponse: Dr. Abu Shams Md. Hasan Ali Masum,Assistant Professor, Department of Nurology, Anwer Khan \\ Modern Medical college. Dhaka. E-mail: hassanalimasum@gmail.com
}

\begin{abstract}
:
Stroke is the third leading cause of death in adult population throughout the world and is the most common cause of severe adult physical disability. It is increasing at an alarming rate in Asia including Bangladesh. The assessment of the frequency of development of various types of complications of stroke is important for proper management after acute stroke and its primary and secondary prevention. The aims of the study were to observe the complications in patients with ischemic and hemorrhagic stroke.A cross sectional observational study was conducted from September 2015 to April 2017 in the department of Neurology, Bangabandhu Sheikh Mujib Medical University, Dhaka. All the patients of ischemic and hemorrhagic stroke confirmed by neuroimaging (CT scan of head/MRI of brain), meeting the inclusion and exclusion criteria were included in the study.Our study was performed with eighty stroke patients. Among them sixty five were ischemic and fifteen were hemorrhagic stroke patients. Present study showed that maximum stroke patients were more than 50 years of age. Mean age of the study population was $59.28 \pm 13.98$ years and $60.07 \pm 17.29$ years in ischaemic stroke patients and haemorrhagic stroke patients respectively. Stroke incidence rate is 1.25 times greater in men than women.
\end{abstract}

University Heart Journal 2019; 15(2): $42-46$

Introduction:

Stroke is the third leading cause of death in adult population throughout the world and is the most common cause of severe adult physical disability. ${ }^{1}$ It is increasing at an alarming rate in Asia including Bangladesh. Post stroke complications are common. The assessment of the incidence of various types of complications of stroke is important for proper management after acute stroke and its primary and secondary prevention. In the present study some relevant risk factors and some demographic profiles like age, sex, residence, occupation, marital status and monthly income were observed. This cross sectional observational study was done of eighty stroke patients to observe to compare the personal profile and risk factors in patients with ischemic and hemorrhagic stroke.

Material and Methods:

A cross sectional observational studywas conducted from September 2015 to April 2017 in the department of
Neurology, BSMMU.Purposive sampling method was followed to collect sample. Eighty stroke patients admitted within 30 days of stroke in the Department of Neurology were included by following inclusion and exclusion criteria.

Inclusion Criteria: Age $\geq 18$ Years, all ischaemic stroke patients admitted within 30 days of stroke, all acute intraparenchymalhaemorrhagic stroke patients including subarachnoid haemorrhage admitted within 30 days of stroke, patients willing to participate in this study.

Exclusion Criteria: Age $<18$ Years, stroke patients admitted after 30 days of onset of stroke, patients or attendants who are not interested to give consent for the study.

Method of Data Collection / Study Procedure After ethical clearance from Institutional Review Board (IRB), patients having features of stroke was selected. After taking proper history and clinical examination, diagnosis of stroke was confirmed by CT scan of Head / 
MRI of brain. Total 80 stroke patients admitted within 30days were selected purposively from Department of Neurology, BSMMU. Informed written consent was taken from each patient or from patient's attendant. On admission stroke severity was calculated on the basis of the National Institutes of Health Stroke Scale (NIHSS). Data was collected from the history, clinical examination findings and investigation reports by filling up the prescribed data collection form.

\section{Data Analysis}

All the data was checked and edited after collection. Data sheets were reevaluated regularly by co-guide and guide. Every steps of the study were completed under proper guidance of guide and co-guide. Descriptive analysis of all relevant variables was done by using measures of central tendency and measures of dispersion. The results were expressed as mean \pm standard deviation (SD) for continuous variables and as frequency, percentage or graph for categorical variables. Qualitative data was analyzed by chi-square test and quantitative data was analyzed by unpaired Student's 't' test according to the objectives of study. Statistical significance was accepted at $P$-value equal to or less than $0.05(\mathrm{P} \leq 0.05)$. Statistical analysis was conducted using a software package, SPSS for Windows, Version 17 (SPSS Inc., Chicago, II, USA).

\section{Results:}

This cross sectional observational study was conducted in the Department of Neurology, Bangabandhu Sheikh Mujib Medical University, Dhaka on the patients with ischemic and hemorrhagic stroke from September 2015 to April 2017. Eighty stroke patients were enrolled in this study of whom 65 patients were ischaemic and 15 patients were haemorrhagic. The results and observations are as follows:

\section{Table-I}

Distribution of the study population by age $(n=80)$

\begin{tabular}{lccc}
\hline Age (years) & $\begin{array}{c}\text { Group-A } \\
\text { (Ischemic } \\
\text { Stroke) } \mathrm{n}(\%)\end{array}$ & $\begin{array}{c}\text { Group-B } \\
\text { (Hemorrhagic }\end{array}$ & p value \\
Stroke) $\mathrm{n}(\%)$ & \\
\hline$\leq 30$ & $3(4.6)$ & $1(6.7)$ & \\
$31-40$ & $4(6.2)$ & $1(6.7)$ & \\
$41-50$ & $13(20.0)$ & $1(6.7)$ & \\
$51-60$ & $13(20.0)$ & $6(40.0)$ & \\
$61-70$ & $23(35.4)$ & $2(13.3)$ & \\
$71-80$ & $6(9.2)$ & $3(20.0)$ & \\
$>80$ & $3(4.6)$ & $1(6.7)$ & \\
Total & $65(100.0)$ & $15(100.0)$ & $0.85^{\text {ns }}$ \\
Mean \pm SD & $59.28 \pm 13.98$ & $60.07 \pm 17.29$ & \\
Range(min-max) & $25-90$ & $18-85$ & \\
* Unpaired t test was done to measure the level of significance. ns \\
$=$ non significant
\end{tabular}

Table I shows distribution of the study population by age. Mean age of the study population was $59.28 \pm 13.98$ years and $60.07 \pm 17.29$ years in group A and group B respectively. There was no significant relationship between age and types of stroke occurred.

\section{Table-II}

Distribution of the study population by gender $(n=80)$

\begin{tabular}{lccc}
\hline Gender & $\begin{array}{c}\text { Group-A } \\
\text { (Ischemic }\end{array}$ & $\begin{array}{c}\text { Group-B } \\
\text { (Hemorrhagic }\end{array}$ & $\mathrm{p}$ value \\
& Stroke) & $\begin{array}{c}\text { Stroke) } \\
\mathrm{n}(\%)\end{array}$ & \\
& $42(64.6)$ & $6(40.0)$ & \\
\hline Male & $23(35.4)$ & $9(60.0)$ & \\
Female & $65(100.0)$ & $15(100.0)$ & $0.52^{\mathrm{ns}}$ \\
\hline
\end{tabular}

*Chi square test was done to measure the level of significance. ns $=$ non significant

Table 2 shows distribution of the study population by gender. No significant relationship was observed between gender and types of stroke occurred.

Table-III

Distribution of the study population by residence $(n=80)$

\begin{tabular}{lccc}
\hline Residence & $\begin{array}{c}\text { Group-A } \\
\text { Ischemic } \\
\text { Stroke) } \\
\mathrm{n}(\%)\end{array}$ & $\begin{array}{c}\text { Group-B } \\
\text { (Hemorrhagic }\end{array}$ & $\mathrm{p}$ value \\
& $\begin{array}{c}\text { Stroke) } \\
\mathrm{n}(\%)\end{array}$ & \\
\hline Urban & $28(43.1)$ & $6(40.0)$ & \\
Rural & $37(56.9)$ & $9(60.0)$ & \\
\hline Total & $65(100.0)$ & $15(100.0)$ & $0.828^{\mathrm{ns}}$ \\
\hline
\end{tabular}

*Chi square test was done to measure the level of significance. $n s=$ non significant

Table 3 shows distribution of the study population by residence. There was no significant relationship between residence and types of stroke occurred.

Table-IV

Distribution of the study population by marital status $(n=80)$

\begin{tabular}{lccc}
\hline $\begin{array}{l}\text { Marital } \\
\text { status }\end{array}$ & $\begin{array}{c}\text { Group-A } \\
\text { (Ischemic } \\
\text { Stroke) } \\
\mathrm{n}(\%)\end{array}$ & $\begin{array}{c}\text { Group-B } \\
\text { (Hemorrhagic } \\
\text { Stroke) }\end{array}$ & $\mathrm{p}$ value \\
$\mathrm{n}(\%)$ & \\
\hline Married & $65(100.0)$ & $14(93.3)$ & \\
Unmarried & 0 & $1(6.7)$ & $0.036^{\mathrm{S}}$ \\
\hline Total & $65(100.0)$ & $15(100.0)$ & \\
*Chi square test was done to measure the level of significance. $\mathrm{s}=$ \\
significant
\end{tabular}


Table 4 shows distribution of the study population by marital status. No significant relationship was observed between marital status and types of stroke occurred.

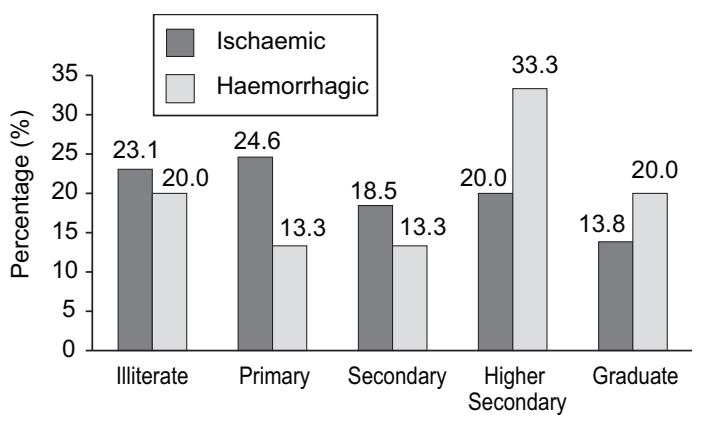

Fig.-1: Distribution of the study population by educational status $(n=80)$.

Figure 1 shows distribution of the study population by educational status. Most of the study populations were literate in group A but maximum of group B were illiterate.

Table-V

Distribution of the study population by occupation $(n=80)$

\begin{tabular}{lccc}
\hline Occupation & $\begin{array}{c}\text { Group-A } \\
\text { (Ischemic } \\
\text { Stroke) } \\
\mathrm{n}(\%)\end{array}$ & $\begin{array}{c}\text { Group-B } \\
\text { (Hemorrhagic } \\
\text { Stroke) }\end{array}$ & p value \\
& $\mathrm{n}(\%)$ & \\
\hline Service holder & $13(20.0)$ & $2(13.3)$ & \\
Businessman & $20(30.8)$ & $4(26.7)$ & \\
Housewife & $22(33.8)$ & $3(20.0)$ & \\
Others & $10(15.4)$ & $6(40.0)$ & \\
\hline Total & $65(100.0)$ & $15(100.0)$ & $0.19^{\mathrm{ns}}$ \\
\hline
\end{tabular}

*Chi square test was done to measure the level of significance. ns $=$ non significant

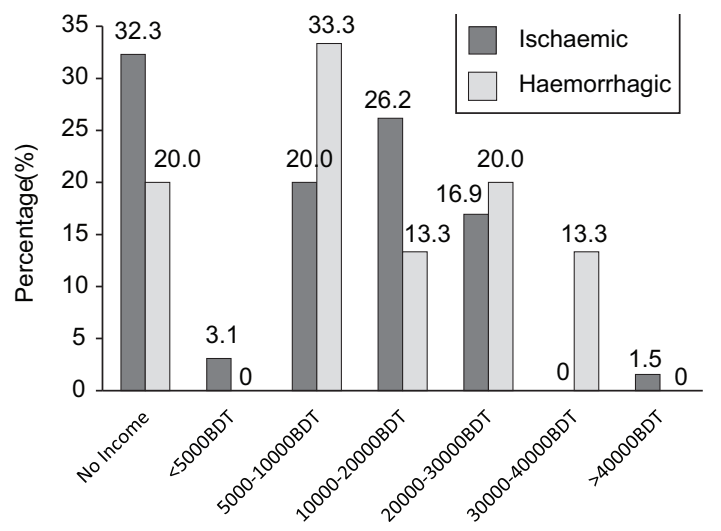

Fig.-2: Distribution of the study population by monthly income $(n=80)$.

Table 5 shows distribution of the study population by occupation. No significant relationship was observed between occupation and types of stroke occurred.
Figure 2 shows distribution of the study population by monthly income. Most of the study populations were of no income category in group A but maximum of group B were in 5000-10000 BDT category.

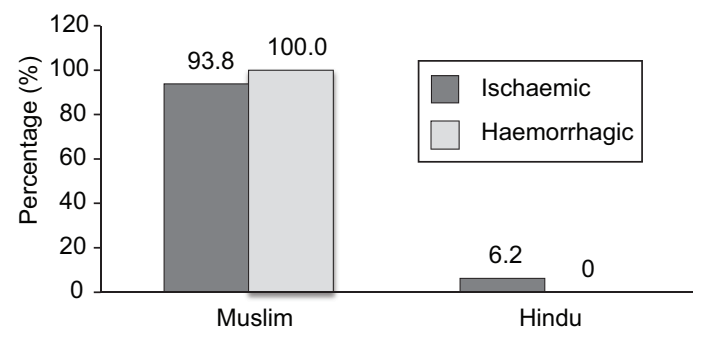

Fig.-3: Distribution of the study population by religion $(n=80)$.

Figure 3 shows distribution of the study population by religion. Almost all of the study populations were Muslims in both group A and group B.

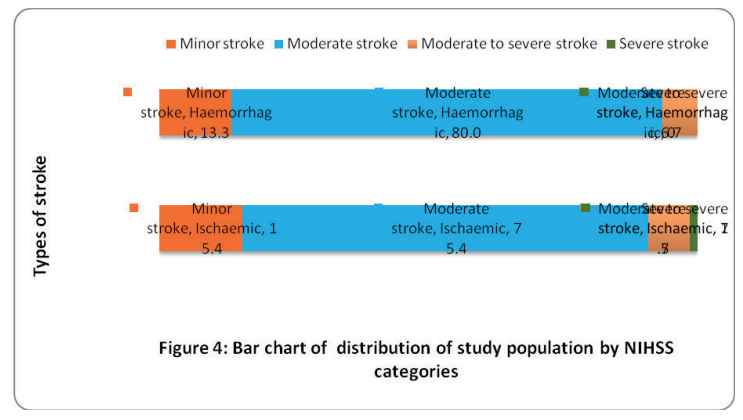

Fig.-4: Bar chart of distribution of study population by NIHSS categories

Figure 4 shows distribution of the study population by NIHSS categories.

Table-VI

Distribution of study population by risk factors $(n=80)$

\begin{tabular}{lccc}
\hline Risk factors & $\begin{array}{c}\text { Group-A } \\
\text { (Ischemic } \\
\text { Stroke) } \\
\mathrm{n}(\%)\end{array}$ & $\begin{array}{c}\text { Group-B } \\
\text { (Hemorrhagic } \\
\text { Stroke) }\end{array}$ & $\mathrm{p}$ value \\
& $\mathrm{n}(\%)$ & \\
\hline Hypertension & $55(84.6)$ & $13(92.9)$ & $0.841^{\mathrm{ns}}$ \\
Diabetes & $21(32.3)$ & $3(21.4)$ & $0.348^{\mathrm{ns}}$ \\
IHD & $18(27.7)$ & $1(7.1)$ & $0.085^{\mathrm{ns}}$ \\
Valvular HD & $6(9.2)$ & 0 & $0.221^{\mathrm{ns}}$ \\
Arrhythmia & $5(7.7)$ & $1(7.1)$ & $0.892^{\mathrm{ns}}$ \\
Dyslipidaemia & $30(46.2)$ & $7(50.0)$ & $0.971^{\mathrm{ns}}$ \\
Previous Vascular event & $37(56.9)$ & $3(21.4)$ & $\mathbf{0 . 0 1 0}$ \\
Drug Abuse & $1(1.5)$ & 0 & $0.629 \mathrm{~ns}$ \\
Smoking & $39(60.0)$ & $13(86.7)$ & $\mathbf{0 . 0 5 0}$ \\
Alcoholism & $1(1.5)$ & $1(7.1)$ & $0.252^{\mathrm{ns}}$ \\
OCP & $1(1.5)$ & 0 & $0.629 \mathrm{~ns}$ \\
Positive family history & $45(69.2)$ & $8(57.1)$ & $0.241^{\mathrm{ns}}$ \\
\hline Total N & 65 & 15 & 80 \\
\hline
\end{tabular}

*Chi square test was done to measure the level of significance. $\mathrm{s}=$ significant $\mathrm{ns}=$ non significant 
Table 6 shows distribution of study population by risk factors. Hypertension is the most common risk factor, followed by positive family history, smoking, previous vascular events, dyslipidemia, diabetes mellitus and ischemic heart disease for both groups of ischemic and hemorrhagic stroke patients. Previous vascular events, family history and IHD were higher in group A than group B. Significance values are noted in previous vascular event and smoking.

\section{Discussion:}

Present study showed that maximum stroke patients were more than 50 years of age. Mean age of the study population was $59.28 \pm 13.98$ years and $60.07 \pm 17.29$ years in group A and group B respectively. Biller et al found that the incidence of stroke increases dramatically with advancing age and increasing age was the most powerful risk factor for stroke. ${ }^{2}$ In a prospective study of 155 patients of acute stroke showed, maximum patients were in the age group of 41-70 years. There were 111 male and 44 female. ${ }^{3}$ So, our study was in concordance with the previous study. In the current study, male were predominant in both groups of stroke patients. Overall, stroke incidence rate is 1.25 times greater in men than women. Men develop ischemic strokes at higher rates than women. ${ }^{2}$ Uddin et al. and Idicula et al. showed that ischemic stroke was more common in male than female. ${ }^{4,5}$ Hannan et al.showed that male to female ratio was $2.53: 1{ }^{3}$ So, our study was in consistent with the previous study.In a cross sectional study carried out in 100 patients of stroke showed, most of the patients suffering from stroke were male and most of them were between 51-70 years of age. Majority were from urban area. Most of the patients were service holders, followed by retired group. Average monthly income of the majority group was less than TK 5000 in a study. ${ }^{6}$ The present study showed that the study population resided almost equally in rural and urban areas. Majority of the stroke patients of the present study were found to be married. Possible explanation for this might be that most of the strokes occurred in elderly population. The current study has also shown that there is no relationship between educational status, religion, occupation, monthly income and types of stroke occurred. Current study shows that hypertension is the most common risk factor, followed by positive family history, smoking, previous vascular events, dyslipidemia, diabetes mellitus and ischemic heart disease for both groups of ischemic and hemorrhagic stroke patients. Previous vascular events, family history and IHD were higher in group A than group B. Significance values were noted in previous vascular event and smoking. Feigin et al. found that cigarette smoking is one of the most important risk factors for stroke. ${ }^{7}$ A study conducted by Putaala et al. stated that smoking is an independent risk factor for silent brain infarcts. ${ }^{8}$ Diabetes was found to be an independent risk factor of ischemic stroke in another study. ${ }^{9}$ Goldstein et al. found that plasma lipids and lipoproteins [total cholesterol, triglycerides, low-density lipoprotein (LDL) cholesterol, HDL cholesterol and lipoprotein] have an influence on the risk of cerebral infarction. ${ }^{10}$ So, this study was consistent with the results of the previous studies.In this study, ischemic stroke was $65(81.3 \%)$ and hemorrhagic stroke was $15(18.7 \%)$, this results are almost similar to a study by Langhorne et al. where it had been shown that ischemic stroke was $85 \%$ and hemorrhagic stroke was $15 \% .{ }^{1}$ In another study conducted by Indredavic et al. also showed that among 489 patients with stroke, $443(90.6 \%)$ patients were ischaemic and $46(9.4)$ patients were haemorrhagic. ${ }^{11}$ Hence, current study can be considered as consistent with the results of the previous studies.

\section{Conclusion:}

This cross sectional study showed that maximum stroke occurred in patients at the age of more than 50 years and male was predominant in both Ischemicand hemorrhagicstroke. Most of the strokes occurred in elderly population.Urban service holders are more affected followed by retired group. Hypertension is the most common risk factor for stroke, followed by positive family history, smoking, previous vascular events, dyslipidemia, diabetes mellitus and ischemic heart disease for both groups of ischemic and hemorrhagic stroke patients.Previous vascular events, family history and IHD were higher in ischemic stroke.Ischemic stroke was four times higher incidence rate than hemorrhagic stroke in this study.Early identification of risk factors and appropriate measures should be taken to prevent stroke and to reduce mortality and morbidity.

\section{References:}

1. Langhorne, P., Stott, D. J., Robertson, L., MacDonald, J., Jones, L., McAlpine, C., Dick, F., Taylor, G. S., Murray, G. Medical Complications after Stroke. Stroke, 2000; 31: 12232.

2. Biller, J., Love, B. B., Schneck, M. J. 'Ischemic Cerebrovascular Disease'. 'In: Daroff, R. B., Fenichel, G. M., Jankovic, J., Mazziotta, J. C.,Sixth edition. Bradley's Neurology in Clinical Practice, Elsevier, Philadelphia, 2012; 1003-5.

3. Hannan, M. A., Rahman, M. M., Haque, A., Ahmed, H. U. 'Stroke: Seasonal variation and association with hypertension'. Bangladesh Medical Research Council, 2001; 27: 69-8. 
4. Uddin M. J., Mondol, B. A., Ahmed, S., Ullah, A. A., Jabber, M. A., Mohammad, Q.D. 'Smoking and ischemic stroke'. Bangladesh Journal of Neuroscience, 2008; 24: 50-4.

5. Idicula, T. T.,Waje-Andreassen, U.,Brog, J., Naess, H. 'Serum albumin in ischemic stroke patients: The Higher the Better'. Cerebrovascular Disease, 2009; 28: 13-7.

6. Hossain, A. M., Ahmed, N. U., Rahman, M., Islam, M. R., Sadhya, G., Fatema, K. 'Analysis of sociodemographic and clinical factors associated with hospitalized stroke patients of Bangladesh'. Faridpur Medical College Journal, 2011; 6: 19-3.

7. Feigin, V. L., Rinkel, G. J., Lawes, C. M., Algra, A., Bennett, D. A., Van G, J., Anderson, C. S. 'Risk factors for subarachnoid hemorrhage'. Stroke, 2005; 36: 2773-0.

8. Putaala, J., Kurkinen, M., Tarvos, V., Salonen, O., Kaste, M., Tatlisumak, T., 'Silent brain infarcts and leukoaraiosis in young adults with first-ever ischemic stroke'. Neurology, 2009; 72: $1823-9$
9. Arboix, A., Milian, M., Oliveres, M., García-Eroles, L., Massons, J. 'Impact of female gender on prognosis in type 2 diabetic patients with ischemic stroke'. European Neurolology, 2006;56: 6-12.

10. Goldstein, L. B, Adams, R., Alberts, M. J., Appel, L. J., Brass, L. M., Bushnell, C. D. 'Primary prevention of ischemic stroke: a guideline from the American Heart Association/American Stroke Association Stroke Council: cosponsored by the Atherosclerotic Peripheral Vascular Disease Interdisciplinary Working Group; Cardiovascular Nursing Council; Clinical Cardiology Council; Nutrition, Physical Activity, and Metabolism Council; and the Quality of Care and Outcomes Research Interdisciplinary Working Group: the American Academy of Neurology affirms the value of this guideline'. Stroke, 2006;37: 1583-9.

11. Indredavik, B., Rohweder, G., Naalsund, E., Lydersen, S., Medical Complications in a comprehensive stroke unit. Stroke,2008; 39: 414-0. 